\title{
Using a model of family adaptation to examine outcomes of caregivers of individuals with autism spectrum disorder transitioning into
}

\author{
adulthood
}

Yue Yu, John H. McGrew, Kevin L. Rand, Catherine E. Mosher

\begin{abstract}
Background: The study examined the burden of caring for individuals with autism spectrum disorder (ASD) transitioning from high school and factors associated with burden derived from the Double ABCX model of family adaptation (i.e., autism symptom severity, problem behaviors, pile-up life demands, personality traits, social support, cognitive appraisals, and coping strategies). In particular, we were interested in the potential association between the "big 5" personality traits and burden.
\end{abstract}

Method: Participants $(N=105)$ were caregivers of individuals with ASD within two years preor post-graduation from high school.

Results: Primary caregivers reported moderate levels of burden. As hypothesized, burden was significantly associated with both child (i.e., increased autism symptom severity and problem behaviors) and caregiver characteristics (i.e., greater neuroticism, lower levels of extraversion, conscientiousness, agreeableness, and social support, and increased use of threat appraisals and passive-avoidance coping strategies). Using multiple regression, increased child behavior problems and increased caregiver use of passive-avoidance coping were identified as independent predictors of burden. Passive-avoidance coping mediated the relationship between caregiver burden and individual personality traits (i.e., neuroticism, extraversion, conscientiousness). 
Conclusions: The results suggest that proximal variables, such as caregivers' use of maladaptive coping strategies, explain the associations between burden and personality. Suggestions for interventions to relieve burden are discussed. 
Using a Model of Family Adaptation to Examine Outcomes of Caregivers of Individuals with Autism Spectrum Disorder Transitioning into Adulthood

Caregivers of individuals with autism spectrum disorder (ASD) report increased distress and poorer psychological outcomes (e.g., stress, depression, anxiety) compared to caregivers of typically developing children (Dunn \& Burbine, 2001) and children with other developmental disabilities (Hayes \& Watson, 2013). Several factors have been associated with this increased burden in caregivers of children with ASD. These factors can be organized using the four components of the Double ABCX model of family adaptation (McCubbin \& Patterson, 1983). The first component (see Figure 1) characterizes the total family demands and needs, starting with the focal stressor, raising a child with ASD (A; e.g., child symptom severity, problem behaviors), then adding general life stressors/pile-up demands affecting the family (aA). The second component characterizes the family/caregiver's internal (B; e.g., personality traits) and external resources (bB; e.g., social support) to meet the demands. The third component characterizes the family/caregiver's interpretation of the demands (C; e.g., threatening) and coping strategies (cC; e.g., problem-focused). Finally, the fourth component is the outcome or the family/caregiver's overall adaptation (X; i.e., caregiver burden - the perception of the negative impact of caregiving on the caregiver's emotional, social, financial, and physical functioning; Zarit, Todd, \& Zarit, 1986).

Results from studies using the Double ABCX model to examine family functioning when raising children with ASD are broadly consistent with the model (e.g., Hall \& Graff, 2012; Manning et al., 2011). For example, variables representative of the first component, greater autism symptom severity, increased problem behaviors (A), and increased pile-up demands (aA) have been consistently associated with poorer family adaptation, e.g., increased parenting stress 
or burden (X; Davis \& Carter, 2008; Stuart \& McGrew, 2009). Similarly, elements representative of the second component, greater autism-specific (e.g., support from physicians, therapists, or others within the autism-community) and general social support (bB; Bekhet, Johnson, \& Zauszniewski, 2012; Khanna et al., 2012) as well as presonality style (B; e.g., optimism; Ekas, Lickenbrock, \& Whitman, 2010) have been related to decreased caregiver burden and maternal distress in parents of those with ASD. Finally, elements from the third component, cognitive appraisals (C) and coping strategies (cC) have been associated as hypothesized to various measures of caregiver and family adaptation (e.g., caregiver burden, parent stress, well-being, depression, family functioning). Specifically, better psychological adaptation has been related to greater use of challenge appraisals and lower use of threat appraisals (C; Manning et al., 2011; Stuart \& McGrew, 2009) as well as to increased problemfocused coping (e.g., initiating actions to alter the situation; Abbeduto et al., 2004; Benson, 2010) and decreased passive-avoidance coping (cC; e.g., denial, avoidance; Hastings et al., 2005) among caregivers of those with ASD. However, the association between emotional approach coping (e.g., positive reappraisal) and outcomes is inconsistent; it was unrelated to maternal depressed mood and caregiver burden (Benson, 2010; Khanna et al., 2011; Stuart \& McGrew, 2009), but predictive of decreased parenting stress (Manning et al., 2011).

\section{Personality Traits}

Lazarus and Folkman (1984) noted that personality factors can play an important role impacting appraisal, coping, and thus stress. Specifically, personal characteristics, such as values and beliefs about oneself and the world, help define individuals' interpretation of stressful encounters and the choice of appraisal style and coping strategy is also often related to personality. Despite the potential importance of personality in understanding caregiver burden, 
studies of personality and caregiver stress in ASD are sparse. Furthermore, the current literature has been largely limited to establishing the association between "healthy" personality traits (e.g., optimism) and stress (Ekas et al., 2010). Similarly, another individual difference variable examined in studies of caregivers' adaptation is the parent's broader autism phenotype (BAP). For example, BAP has been shown to be associated with parenting stress, coping strategies, and social support (Ingersoll \& Hambrick, 2011). To our knowledge, however, no studies in ASD have embedded the exploration of stress and personality within a larger conceptual framework, such as the "big 5" personality traits. Although Jobe and Glidden (2008) examined the "big 5" personality traits in caregivers of individuals with developmental disabilities, reporting that high neuroticism and low extraversion were related to greater transition-related worries and fewer transition-related rewards, the authors did not separately analyze caregivers of those with ASD, limiting its relevance for ASD.

The potential importance of the "big 5" personality traits for understanding caregiver stress has been consistently shown in studies of the stress of caring for people with disabilities, generally. For example, in caregivers of adults with dementia and adults with multiple functional impairments, those high in neuroticism report greater caregiver burden, depression, and poorer mental and physical health (Melo, Maroco, \& De Mendonça, 2011; Van der Lee, Bakker, Duivenvoorden, \& Dröes, 2014); whereas, those high in extraversion and conscientiousness report better physical and mental health, social support satisfaction, and decreased burden (Löckenhoff, Duberstein, Friedman, \& Costa, 2011; Melo et al., 2011). In contrast, the relationship between caregiver outcomes and agreeableness and openness has been inconsistent, with some studies reporting a weak association and others finding none (Jobe \& Glidden, 2008; Löckenhoff et al., 2011). 
In addition to whether personality impacts burden, another critical area for investigation is how personality affects burden (i.e., what are the potential mediators between personality and burden?). For example, in dementia caregivers, neuroticism has been related to less perceived social support and greater burden (Shurgot \& Knight, 2005); whereas, extraversion has been related to greater social support satisfaction and better psychological outcomes (Reis et al., 1994). This suggests that social support may help explain or mediate the relationship between burden and personality. Similarly, individuals with high levels of neuroticism tend to practice passive-avoidance coping and use threat appraisals; whereas, individuals high in extraversion and conscientiousness are more likely to use problem-focused coping (Connor-Smith \& Flachsbart, 2007; Penley \& Tomaka, 2002). Moreover, higher levels of passive-avoidance coping and threat appraisals have been related to negative outcomes (Hastings et al., 2005; Paynter, Riley, Beamish, Davies, \& Milford, 2013). Thus, although not examined directly, these results suggest that coping and appraisal style may help explain and perhaps mediate the associations between personality traits and individual outcomes.

\section{The Transition Period}

Although ASD is a chronic disorder (Cadman et al., 2012), with problems with daily living skills and poor community outcomes extending into adulthood (e.g., high unemployment rates, frequent job losses, and underachievement in education; Howlin, Goode, Hutton, \& Rutter, 2004), studies of caregiver burden and family adjustment in ASD have largely focused on childhood (Hayes \& Watson, 2013). Similarly, studies often overlook the temporal factors impacting stress/burden, uncritically including caregivers of children at different ages. This complicates both within- and between-study comparisons and ignores the potential impact of differing developmental periods on caregiving demands. In contrast, stress/burden may be 
highest at specific ages corresponding to developmental or illness milestones (e.g., immediately after receiving the ASD diagnosis; McGrew \& Keyes, 2014; Stuart \& McGrew, 2009).

Accordingly, the current study focuses on a specific time frame, the transition from high school, which can be especially stressful because the person with ASD and caregivers are facing increased uncertainties and challenges (Blacher, 2001). Children may seek increased independence while still exhibiting dysfunctional behaviors, and at the same time, parents need to take on multiple roles, some of which are unique to this transition, such as advocates, collaborators, and decision makers, yet feel unequipped to deal with the heightened levels of responsibility (Bianco, Garrison-Wade, Tobin, \& Lehmann, 2009; Jobe \& Glidden, 2008). For example, advocacy during adulthood transition is different from earlier years in the school system when parents can rely on the public education law (Van Bourgondien, Dawkins, \& Marcus, 2014). Moreover, caregivers often must cope with limited resources and extra demands, with increased intensity relating to time, effort, and complexity of their involvement (Bianco et al., 2009; Cadman, Eklund, et al., 2012; Chambers \& Hughes, 2004; Hanley-maxwell, Whitneythomas, \& Pogoloff, 1995). Parents often feel that they are back to "square one" and have to readjust their advocacy skills to new challenges facing multiple systems (e.g., social security, vocational rehabilitation) and uncertainty in public funds (Van Bourgondien et al., 2014).

\section{The Current Study}

The study had three aims: (1) to determine the degree of burden for caregivers of individuals with ASD during the transition from high school; (2) to test the association between burden and elements of the Double ABCX model, as a whole and individually, including the association between caregiver personality and burden; and (3) to examine potential mediators of this association. Several hypotheses were examined. Specifically, caregiver burden was posited 
to be higher with: 1) higher levels of autism symptom severity, problem behaviors, pile-up demands, and transition-related demands, 2) higher levels of caregiver neuroticism and lower levels of extraversion or conscientiousness, 3) lower perceived social support, 4) greater use of threat appraisals and lower use of challenge appraisals, and 5) greater use of passive-avoidance coping and lower use of problem-focused coping and emotional approach coping. Mediation analyses were exploratory and focused on the personality traits consistently related to burden in the empirical literature (i.e., conscientiousness, extraversion and neuroticism).

\section{Methods}

\section{Sample}

Participants were recruited using multiple methods, including contacting state and national autism-related organizations and listservs and distributing flyers at local autism events. Most participants were recruited using Amazon Mechanical Turk (MTurk), an online marketplace connecting interested parties for business, including recruiting participants for research. MTurk is increasingly used as a recruitment method for psychological studies and has generally been found to produce samples comparable or superior to other online recruitment methods. For example, Dworkin et al. (2016) compared three online recruitment strategies for recruiting parents: email listservs, Facebook, and MTurk and found that MTurk had the most demographically diverse sample. In addition, Casler and colleagues (2013) found that the performance in a behavioral task across samples recruited via MTurk, face to face, or social media was indistinguishable.

To be included, participants had to be caregivers of individuals with ASD within two years pre- or post-graduation from high school. ASD status was confirmed by parent-reported formal diagnosis from a licensed psychologist or medical professional and by scores on the 
Social Communication Questionnaire (SCQ score >11; Rutter, Bailey, \& Lord, 2003).

Participants completed questionnaires using Qualtrics directly through MTurk or via an email link. MTurk participants $(n=156)$ received five-dollars in MTurk credits. Other participants $(n=$ 15) received five-dollar e-gift cards.

\section{Measures}

Symptom severity and problem behaviors (A). The 40-item Social Communication Questionnaire, Current form (SCQ; Rutter et al., 2003) parent self-report measure, was used to confirm ASD diagnosis and to measure autism symptom severity. Scores greater than 11 indicate the likelihood of an ASD diagnosis with good sensitivity (.85) and specificity (.75; Norris \& Lecavalier, 2010). Internal consistency was acceptable in a prior study (Cronbach's $\alpha=.80$; Manning et al., 2011) and in the current study $(\alpha=.60)$.

The 30-item Problem Behavior Rating Scale (PBRS; Stone et al., 2010) parent self-report instrument was used to measure problem behaviors in individuals with ASD. Items were rated on a 4 -point Likert scale $(1=$ not at all problematic; $4=$ very problematic $)$. The PBRS had good internal consistency in prior research $(\alpha=.88$; Stone et al., 2010) and in the current sample $(\alpha=$ $.92)$.

Pile-up demands (aA). A modified version of the 43-item Social Readjustment Rating Scale (SRRS; Holmes \& Rahe, 1967) assessed general stressful life events. The modification uses a 6-point Likert scale to rate items $(0=$ not experienced; $5=$ experienced with extreme distress). The SRRS had good internal consistency in prior studies $(\alpha=.87$; Stuart $\&$ McGrew, $2009)$ and in the current study $(\alpha=.90)$.

A five-item author-created Transition Stressor Questionnaire (TSQ) assessed transitionrelated demands. The questionnaire was developed using a theoretical approach. Items were 
created to assess the degree to which transition created "A demand ... the external environment acting on the individual" (Glidden, 1993, p.483) that resulted in changes in life requiring adaptation struggles (Lazarus, 1990). Parents of young adults with developmental disabilities have reported that transition adaptation requires increased intensity in time, effort and complexity of their post-high school involvement (Bianco et al., 2009). The goal of this scale therefore was to measure the demands associated with taking care of a child with ASD during the transition period by quantifying the time and energy parents expend in transition-related activities and changes in their daily activities, including family, social, and work. Specifically, the five items assessed time/effort spent on planning (Q1), and on thinking, pursuing answers, or discussing children's transition (Q2) and degree to which normal family (Q3) social (Q4) and work activities (Q5) changed. Items were rated using a 5-point Likert scale $(1=$ none; $5=$ a lot $)$. An example question was "How much time and energy have you spent thinking about, actively pursuing answers about, or discussing with other people your child's transition?" The focus for each question was to assess the transition related demands/stressors (how much time or effort did you exert) rather than reactions to those demands or stress (how did this make you feel). Refer to the appendix for a copy of the TSQ and endorsement in each item (Appendix A and Table 6). The TSQ had good internal consistency $(\alpha=.81)$.

Personality traits (B). The 60-item NEO Five Factor Inventory (NEO-FFI; Costa \& McCrae, 1992) assessed personality traits. Items were rated using a 5-point Likert scale ( $1=$ strongly disagree; $5=$ strongly agree). The five subscales had acceptable test-retest reliability (.86 to .90$)$ and internal consistency (.68 to .86) in prior studies (Costa \& McCrae, 1992). Internal consistency for the five subscales was similar in the current sample $(\alpha=.70$ to .90$)$. 
Social support (bB). The 12-item Multidimensional Scale of Perceived Social Support (MSPSS; Zimet et al., 1988) assessed general social support and the eight-item Contextual Perceived Social Support (CPSS; Stuart \& McGrew, 2009) assessed support from the autism community. Items on both scales were rated on a 7-point Likert scale $(1=$ very strongly disagree; 7 = very strongly agree). Internal consistency for both scales was good in prior studies (MSPSS: $\alpha=.92$, Zimet, 1998; CPSS: $\alpha=.88$, Stuart $\&$ McGrew, 2009) and in the current sample (MSPSS: $\alpha=.96$; CPSS: $\alpha=.94)$.

Cognitive appraisal (C). The 28-item Stress Appraisal Measure (SAM; Peacock \& Wong, 1990) assesses primary and secondary appraisal. Because we were interested in assessing primary appraisals, only threat (four items) and challenge appraisals (four items) were examined, based on Lazarus and Folkman's (1984) emphasis on these aspects when discussing primary appraisal, as well as on empirical evidence using the SAM measure that challenge and threat styles are the most stable (Roesch \& Rowley, 2005). Items were rated on a 5-point Likert scale $(1=$ not at all; $5=$ extremely $)$. Internal consistency was acceptable in prior studies $(\alpha=.71$ to .90 ; Kausar \& Powell, 1999) and in the current sample ( $\alpha=.67$ to .68).

Coping strategies (cC). The 28-item Brief COPE (Carver, 1997) assessed coping strategies. Items were rated on a 4-point Likert scale $(1=\mathrm{I}$ haven't been doing this at all; 4 = I've been doing this a lot). The 14 subscales were categorized into problem-focused, emotional approach, and passive-avoidance coping scales (Stuart \& McGrew, 2009). Internal consistency for the three scales ranged from adequate to good in a prior study $(\alpha=.60$ to .81 ; Stuart $\&$ McGrew, 2009) and was better in the current sample ( $\alpha=.77$ to .84$)$.

Caregiver burden (X). The 21-item Caregiver Strain Questionnaire (CGSQ; Brannan, Heflinger, \& Bickman, 1997) measured caregiver burden. Items were rated using a 5-point Likert 
scale $(1=$ not at all a problem; $5=$ very much a problem $)$. The CGSQ has three subscales: objective strain (i.e., observable, negative occurrences of caregiving), internalized subjective strain (i.e., expediting negative feelings), and externalized subjective strain (i.e., negative feelings toward the child). Total scale internal consistency was good in a prior study $(\alpha=.94$; Stuart \& McGrew, 2009) and in the current sample $(\alpha=.94)$. The subscales had adequate internal consistency in prior studies ( $\alpha=.75$ to .93 ; Khanna et al., 2012) and in the current study $(\alpha=.84$ to .87$)$.

Attention check. To ensure participants' attentiveness while completing the survey, three attention-check items were inserted at various points within the overall survey, e.g., please respond to this item by selecting "Neutral." Prior studies indicate that this is a helpful approach to identify participants who are not attentive to instructions or to survey questions (Chituc, Henne, Sinnott-Armstrong, \& De Brigard, 2016; Roehrig, Thompson, \& Cafri, 2008).

\section{Statistical Design and Data Analysis}

Statistical analysis was performed using SPSS 23.0 (IBM Corp. Released, 2015).

Descriptive statistics were used to characterize demographic information and caregiver burden during the transition period. One-tailed Pearson correlations were used to test the hypotheses, which were all directional, and two-tailed Pearson correlations were conducted for the nondirectional exploratory analyses. Hierarchical regression was used to examine potential elements of the Double ABCX model associated with burden. Mediation analyses were performed with the SPSS PROCESS module using a parallel mediation model with multiple mediators, thus allowing for comparison of the size of indirect effects and increased power for tests of indirect effects (Hayes, 2013).

\section{Results}




\section{Participants}

Of the 171 participants completing the survey, 156 individuals were recruited via MTurk and 15 via other methods. Sixty-six participants were excluded from the data analyses $(n=61$ from MTurk) for not meeting the inclusion criteria ( $n=31$; e.g., graduation date outside the twoyear window, $\mathrm{SCQ}<11)$, answering one or more attention-check questions incorrectly $(n=12)$, or providing invalid or inconsistent responses other than the attention-check questions $(n=23$; e.g., took the survey more than once; mismatch between graduation date and current academic status). The data were then examined for outliers, normality, linearity, and homogeneity. Three individuals had data indicating one or more extreme scale outliers ( $>3 \mathrm{SD})$. Extreme scale scores were adjusted using winsorizing, yielding a final sample of 105 for data analysis.

Participants' average age was $43.0(S D=5.4$; see Table 1$)$. Slightly more participants were fathers $(54.3 \%, n=57)$ than mothers of individuals with ASD $(45.7 \%, n=48)$. Over half were white $(83.8 \%, n=88)$, married $(71.4 \%, n=75)$, working full time $(78.1 \%, n=82)$, and had a college degree or higher $(55.3 \%, n=58)$. The average age of participants' children with ASD was $17.4(S D=1.5)$; the majority were male $(81.9 \%, n=86)$ and had not yet graduated $(72.4 \%$, $n=76$ ). Over half intended to or currently attended college/university or vocational school $(61.9 \%, n=65)$, and the vast majority were living with or had plans to live with parents after high school graduation $(80.0 \%, n=84)$.

\section{Preliminary Analyses}

Table 2 displays the means, standard deviations, and confidence intervals for study variables. No significant relationships were found between caregiver burden and parent (i.e., gender, age, education level, annual income) or child demographic variables (i.e., gender, age, current academic status; $p s>.05)$, except for receiving therapy or special services $(r=.20, p=$ 
$.041)$. We also explored caregiver gender differences on the study variables. Fathers $(M=2.15$, $S D=.70)$ and mothers $(M=2.10, S D=.78)$ reported similar levels of caregiver burden, $t(103)=$ $.31, p=.757$. Three of the 17 variables from the $\mathrm{ABCX}$ model indicated a gender difference: neuroticism $\left[M_{\text {female }}=33.08, S D_{\text {female }}=10.18\right.$ vs. $M_{\text {male }}=29.04, S D_{\text {male }}=8.47, t(103)=-2.23, p=$ $.028]$, extraversion $\left[M_{\text {male }}=40.75, S D_{\text {male }}=6.32\right.$ vs. $M_{\text {female }}=38.02, S D_{\text {female }}=7.82, t(103)$ $=1.98, p=.050]$, and social support from the ASD community and providers $\left[M_{\text {male }}=5.43\right.$, $S D_{\text {male }}=1.06$ vs. $\left.M_{\text {female }}=4.92, S D_{\text {female }}=1.31, t(103)=2.20, p=.030\right]$. However, because none of the gender differences were hypothesized, when we applied the Benjamini and Hochberg False Discovery Rate (1995) to protect against potential Type 1 error inflation when using multiple t-tests, none of the gender differences remained significant.

\section{Do Caregivers Report Increased Demands (aA) and Burden (X) During Transition?}

Pile-up demands and transition-related demands measured levels of general and specific stressors during the transition ( $\mathrm{aA}$ in the $\mathrm{ABCX}$ model). The mean score for pile-up demands was $18.07(S D=14.69)$, indicating mild general demands. Compared to the period after receiving the initial ASD $(M=19.71, S D=17.68$; Stuart $\&$ McGrew, 2009), pile-up demands were similar during the transition, $t(181)=.68, p=.495$.

Participants reported moderate to high transition-related demands $(M=2.90, S D=.89)$. Using the scale midpoint as the threshold for significant stressor levels (i.e., scores of three [some to a lot] or higher), $90 \%$ of participants reported significant stressor levels for their efforts in planning for their child's transition, $82 \%$ for the time and energy spent thinking about, actively pursuing answers, or discussing with others the child's transition, $46 \%$ for changing family activities for transition planning, $42 \%$ for changing social activities, and $36 \%$ for changing work activities. 
Parents reported moderate levels of caregiver burden $(M=2.13, S D=.74)$, indicating that on average participants endorsed each of the 21 items as being a little bit of a problem. About $30 \%$ of the participants scored 2.5 or higher on the overall caregiver burden scale, indicating that on average every item on the scale was rated as being between a little bit of problem and a problem. When the three CGSQ subscales were examined, parents reported the highest levels of internalized subjective strain $(M=2.55, S D=.92)$ and lower levels of objective caregiver strain $(M=2.05, S D=.76)$ and externalized subjective caregiver strain $(M=1.69, S D=$ .85; see Table 2). At the item level, parents scored highest on the item "feeling worried about child's future" $(M=3.32, S D=1.23)$. Compared to the period after the initial ASD diagnosis, parents reported significantly less burden during the transition period $(M=2.54, S D=.90$; Stuart $\&$ McGrew, 2009), $t(181)=3.38, p<.001$.

\section{Test of Hypotheses}

One-tailed Pearson correlations were computed to examine the relationship between caregiver burden and the hypothesized predictors (see Table 3 ). Consistent with predictions, greater caregiver burden was associated with greater autism symptom severity $(r=.25, p=.006)$, increased problem behaviors $(r=.50, p<.001)$, greater pile-up demands $(r=.20, p=.021)$, greater transition-related demands $(r=.28, p=.002)$, higher neuroticism scores $(r=.46, p$ $<.001)$, greater use of threat appraisals $(r=.48, p<.001)$, and more use of passive-avoidance coping $(r=.69, p<.001)$. Also, as predicted, lower caregiver burden was related to higher levels of extraversion $(r=-.26, p=.004)$ and conscientiousness $(r=-.31, p=.001)$, and higher levels of general $(r=-.31, p=.001)$ and contextual social support $(r=-.19, p=.028)$. In contrast, caregiver burden was unrelated to the use of challenge appraisals $(r=-.11, p=.135)$, and use of either problem-focused coping $(r=.10, p=.156)$ or emotional approach coping $(r=.08, p=$ 
.203). The associations between caregiver burden and openness and agreeableness were examined using two-tailed Pearson correlations. Burden was negatively related to agreeableness $(r=-.21, p=.030)$ and openness $(r=-.19, p=.048)$.

\section{Regression}

Hierarchical regression was used to examine the potential associations between elements of the Double ABCX model and caregiver burden (See Table 4 and Table 5). Overall, the model accounted for $63 \%$ of the variance in caregiver burden, $R=.79, F(15,85)=9.58, p<.001$. Problem behaviors $(\beta=.25, p=.005)$ and passive-avoidance coping $(\beta=.41, p<.001)$ were retained in the final model, explaining over half of the variance in caregiver burden.

\section{Mediation}

Mediation analyses were conducted separately for conscientiousness, extraversion, and neuroticism. Potential mediators were variables that demonstrated significant Pearson correlations with the personality traits (see Figure 2 and Table 5). Passive-avoidance coping (indirect effect $=.02, S E=.01,95 \% \mathrm{CI}=.01, .03)$ and threat appraisal (indirect effect $=.004, S E$

$=.00,95 \% \mathrm{CI}=.0001, .01)$ mediated the relationship between neuroticism and caregiver burden. Participants high in neuroticism reported increased use of passive-avoidance coping and threat appraisals, which were associated with greater caregiver burden. Similarly, passive-avoidance coping mediated the relationships between caregiver burden and both extraversion (Indirect effect $=-.02, S E=.01,95 \% \mathrm{CI}=-.04,-.01)$ and conscientiousness $($ Indirect effect $=-.02, S E=$ $.01,95 \% \mathrm{CI}=-.04,-.01)$. Participants high in extraversion or conscientiousness reported decreased use of passive-avoidance coping, which was related to lower burden. Finally, problemfocused coping (Indirect effect $=.01, S E=.01,95 \% \mathrm{CI}=.003, .03)$ mediated the relationship 
between conscientiousness and burden. Participants high in conscientiousness reported increased use of problem-focused coping, which was associated with greater caregiver burden.

\section{Discussion}

\section{Caregiver Demands and Burden in the Transition Period}

Overall, parents reported moderate levels of stressors and stress during the child's transition to adulthood. Most participants experienced increased demands from planning, gathering information, and thinking about the transition. Nearly half of caregivers also reported adjusting activities due to transition planning. The highest burden subscale scores were for negative feelings, such as worry, guilt, and unhappiness (Khanna et al., 2012). Furthermore, consistent with the demands of the transition period, the most highly endorsed aspect of caregiving burden was worrying about their child's future.

Although stressed during the transition period, caregivers were less burdened than a comparison group of caregivers recently learning that their child had ASD (Stuart \& McGrew, 2009). Sampling differences between the studies may explain some of this difference. It is also possible that by the time children with ASD go through transition, families have more strategies and resources to handle stress related to raising their child, reducing caregiver burden (Manning et al., 2011; Smith, Seltzer, Tager-Flusberg, Greenberg, \& Carter, 2008). Consistent with this notion, Barker et al. (2011) found evidence of long-term resilience in mothers of adolescents and adults with ASD. Specifically, parent depressive symptoms did not increase and anxiety declined across the 10-year period examined.

These results are broadly consistent with the idea that levels of burden and stress may vary over time and at particular developmental milestones. That is, although ASD is a lifelong disorder that continues to impact the family, the specific demands and the resulting distress wax 
and wane. In contrast, the factors associated with burden (e.g., problem behaviors) seem to be relatively constant. Those found to affect parents' well-being in other studies and time periods (Abbeduto et al., 2004; Stuart \& McGrew, 2009) still appeared to be impactful during the transition period.

\section{Predictors of Burden in the Transition Period}

We adopted the Double ABCX model (McCubbin \& Patterson, 1983) as a framework for understanding factors associated with caregiver burden during the transition period and most of the hypotheses based on the model were supported. For example, both ASD-specific (i.e., symptom severity, problem behavior, transition-related demands) and general life strain (i.e., pile-up demands) indicators of demand (A in the model) were related to increased caregiver burden. This is consistent with theory (Lazarus \& Folkman, 1984) and with prior empirical research (Davis \& Carter, 2008; Ekas et al., 2010; Hall \& Graff, 2012; Manning et al., 2011). Theoretically, the greater the demands of the stressor (e.g., problem behaviors), the greater the subjective stress (e.g., caregiver burden). The results also suggest that more specific or proximal measures of caregiving demands (i.e., transition-related demands or problem behaviors) are stronger predictors of caregiving burden than general stressors (i.e., pile-up demands).

As predicted, social support also was associated with decreased burden during the transition period (external resources, labeled B in the model). However, general support from families and friends demonstrated a stronger association with burden than support from the autism community and providers both in the current and prior studies (Bristol, 1987; Gill \& Harris, 1991; Smith, Greenberg, \& Seltzer, 2012). For example, White and Hasting (2004) found that informal sources of support (e.g., spouse, family, friends, etc.) was most reliably associated with well-being in parents of adolescents with intellectual disabilities even when controlling for 
child characteristics, but formal professional support was not associated with parental wellbeing. Thus, although contextual support may be helpful in decreasing burden related to a child's needs, the broader support provided by family and friends appears to be more helpful overall.

A primary research question was whether caregiver burden was related to personality traits (labeled B in the model) as measured by the "big 5." The results consistently indicated that personality explains, at least in part, differences in burden for those caring for someone with ASD. Specifically, burden was positively related to neuroticism and negatively related to conscientiousness, extraversion, openness, and agreeableness. Importantly, although prior studies have reported associations between the "big 5" and outcomes in related samples (Jobe \& Glidden, 2008; Yamada et al., 2012), to our knowledge, this is the first study to demonstrate a link between personality and burden in a sample of caregivers of persons with ASD.

Neuroticism clearly demonstrated the strongest association with burden across the five traits, and the fourth strongest association overall, after passive-avoidance coping, problem behaviors, and threat appraisals. Consistent with our findings, neuroticism has been found to be a strong predictor of negative outcomes for caregivers generally, including in caregivers of children with developmental disability (DD) and typically developing children (Jobe \& Glidden, 2008; Prinzie, Stams, Deković, Reijntjes, \& Belsky, 2009) as well as in caregivers of adults with cancer and older adults with multiple functional impairments (Kim, Duberstein, Sörensen, \& Larson, 2005; Löckenhoff et al., 2011). Also, neuroticism shows the strongest association with caregiver burden and depression in caregivers of individuals with mental health issues (e.g., schizophrenia, dementia; Lautenschlager et al., 2013). This suggests that a tendency to experience more negative emotions substantially decreases the ability to cope with the burden of caring for a child with a disability such as ASD. 
In contrast, as predicted, extraversion and conscientiousness were related to lower levels of caregiver burden. These results are consistent with prior studies relating both traits to better physical and mental outcomes in caregivers of children with DD (Jobe \& Glidden, 2008; Yamada et al., 2012) and in dementia caregivers (Melo et al., 2011), and relating extraversion to lower parenting stress in the general population (Rantanen et al., 2015). This suggests that being open to and seeking social connections as well as being prudent, dependable, well organized, and persistent in dealing with concerns could alleviate the burden of caring for someone with ASD. Importantly, conscientiousness has emerged as a robust predictor of health outcomes (e.g., longevity) across a variety of diagnoses highlighting the potential importance of perseverance in relieving stress and burden generally (Friedman \& Kern, 2014).

Although not predicted, caregivers high in agreeableness and openness also reported lower levels of burden, although the associations were weak. This suggests that being trusting, altruistic, compliant, tender-minded and able to adjust to novel situations could help alleviate the stress of caring for a child with ASD (Yamada et al., 2012).

Consistent with Lazarus and Folkman's model of stress (1984), the variables with the strongest association to burden were appraisals and coping (labeled $\mathrm{C}$ in the model). For example, use of threat appraisals was associated with greater burden nearly as strongly as problem behaviors. Challenge appraisals, however, were unrelated to burden. The relative weakness of challenge vs. threat appraisals is consistent with prior evidence that burden is more strongly related to increased negative appraisals than to decreased positive appraisals in studies across several caregiver groups, including caregivers of ASD (McGrew \& Keyes, 2014), multiple sclerosis (Pakenham, 2001), and HIV/AIDS (McCausland \& Pakenham, 2003). Moreover, negative and positive stress appraisals may be differentially related to negative and 
positive outcomes for health generally. In a study of appraisals in the general population, threat appraisals predicted greater negative affect and perceived stress, whereas challenge appraisals were related to greater positive affect (Maier et al., 2003). Thus, challenge and threat appraisals may be associated with positive and negative outcomes, respectively (Lazarus \& Folkman, 1984).

As predicted, use of passive-avoidance coping was strongly related to increased caregiver burden, bivariately and multivariately, and demonstrated the strongest association to burden overall. This result is consistent with prior studies of outcomes in ASD caregivers (e.g., Hasting et al., 2005) and of stress in general samples, where avoidance coping has been consistently shown to be the strongest predictor of stress both longitudinally and in meta-analyses (Holahan, Moos, Holahan, Brennan, \& Schutte, 2005; Penley, Tomaka, \& Wiebe, 2002). Theoretically, too, avoidance is viewed as less adaptive than other forms of coping because neither the problem nor the emotional reaction to stress is addressed, leading to increased negative outcomes (Lazarus \& Folkman, 1984).

In summary, as illustrated above, each of the elements of the Double ABCX model were useful in describing and identifying factors related to burden, explaining over half of the variance in caregiver burden. Moreover, the model seems to have robust generalizability and applicability across the life span and provides a useful framework for understanding family outcomes for ASD (Manning et al., 2011; Pakenham et al., 2005) as well as for other diagnoses and conditions (e.g., intellectual disability, tracheostomy; Joseph, Goodfellow, \& Simko, 2014; Saloviita, Italinna, \& Leinonen, 2003). Although bivariately each of the model elements emerged as useful, multivariately only problem behaviors and passive-avoidance coping were independent predictors of caregiver burden. Given the high correlations among the predictors, it is not 
surprising that only two variables independently emerged in the regression. Moreover, the two variables that emerged have been identified as highly predictive of stress in prior studies (Davis \& Carter, 2008; Manning et al., 2011). Problem behavior, an indicator of demand, was identified as the strongest predictor of parenting stress in a meta-analysis (Hayes \& Watson, 2012).

Furthermore, as noted above, passive-avoidance coping showed the strongest bivariate association both with burden in the current sample and with stress in general populations (Penley et al., 2002).

\section{How Do Personality Traits Impact Caregiver Burden}

A critical unanswered question is how personality impacts burden. Passive-avoidance coping was consistently found to mediate the link between personality and burden. For example, neuroticism had an indirect impact on burden through passive-avoidance coping, indicating that caregivers high in neuroticism tended to use more passive-avoidance coping, which was in turn related to greater burden. Previous studies have also shown that neuroticism is related to the use of problematic coping strategies, such as wishful thinking and withdrawal (Connnor-Smith \& Flachsbart, 2007). Similarly, extraversion and conscientiousness were related to decreased burden through decreased use of passive-avoidance coping. These findings are consistent with prior research that individuals high in both traits report greater use of problem solving and cognitive restructuring and less use of maladaptive coping efforts (Connor-Smith \& Flachsbart, 2007). A consistent finding across all three traits then is that passive-avoidance coping mediates burden. This suggests strongly that the links between personality and poor caregiver outcomes can be explained in part by the maladaptive coping strategies individuals use.

Although problem focused coping was not related to burden bivariately, it emerged as a positive mediator of the correlation between conscientiousness and burden. The positive sign can 
seem counterintuitive (more problem focused coping is associated with more burden). However, the literature is actually mixed concerning the expected direction of the relationship between problem-focused coping and stress, which has been negatively associated (Abbeduto et al., 2004; Folkman et al., 1986), unrelated (Baum, Fleming, \& Singer, 1983; Nelson \& Sutton, 1990), and positively associated with measures of stress and distress (Pottie \& Ingram, 2008). Because high stress situations demand greater efforts to cope, decreased levels of problem-focused coping may be the result and not the cause of lower levels of demand or stress. That is, it may not be that more coping "leads" to more stress, rather, more stress may require more need to cope. Additionally, these disparate findings may be explained by the matching hypothesis (Folkman \& Moskowitz, 2004). That is, the usefulness of a coping style may depend on the type of problem (Pearlin \& Schooler, 1978). For example, unsolvable problems may be better approached through use of emotional approach strategies. It may be that when facing chronic demands, such as taking care of a child with ASD or helping him/her through the transition period, it is difficult to "fix" the actual source of the problem, and the use of problem-focused coping may be counterproductive.

Finally, it is worth noting that the correlations between personality traits and burden, although often substantial, e.g., neuroticism, could be completely explained by other variables in the Double ABCX Model, such as coping style. This suggests that the assessment of personality, while of theoretical interest to our understanding of burden, failed to add incremental predictive validity. In addition, given that traits are generally viewed as non-modifiable, they may be of less practical import in identifying targets for intervention.

\section{Study Limitations}


The study has several limitations. The sample may not be representative of parents with ASD, limiting generalizability. The majority of participants were white and of higher socioeconomic status; additionally, more than half of their children with ASD were planning to or going to college or vocational school, indicating a higher functioning sample of individuals with ASD. However, in contrast to most studies, our sample contained a nearly equal number of fathers and mothers, suggesting that the results should be generalizable to both genders. Related to this limitation, most participants were recruited through MTurk, and all participants completed the survey online, suggesting a potential bias towards computer savvy participants with ready access to computers. In addition, the rate of unusable responses from MTurk was relatively high (30\%), suggesting limits on the efficiency and validity of data collection on MTurk, at least for clinical samples. However, as noted earlier, MTurk generally produces samples that are comparable to other online recruitment methods. Moreover, the nearly approximately equal caregiver gender distribution is consistent with the samples recruited through MTurk in general (Shapiro, Chandler, \& Mueller, 2013) and in parents specifically (Dworkin et al., 2016). The cross-sectional study design also was a limitation, compromising our ability to make causal inferences and to fully examine questions regarding mediation, which requires longitudinal data to identify direction.

\section{Implications}

Overall, the findings suggest several intervention targets to reduce parent burden and stress, such as community-based programs to provide emotional and tangible support or assistance to parents to handle behavioral problems and thus reduce burden. Providers of families raising children with ASD also should be encouraged to be sensitive to parents' stress and ready to provide support. Parent interventions targeting the use of threat appraisals and passive- 
avoidance coping may be particularly helpful. Training in parent activation (Pennarola et al., 2012), for example, could help decrease the use of passive-avoidance coping, thus, decreasing burden.

Professionals also may wish to target the emotions, behaviors, and attitudes associated with specific personality traits to help parents reduce stress more effectively. For example, individuals with high levels of neuroticism have a tendency towards negative affect (e.g., fear, sadness, anger, guilt; Melo et al., 2011). Taking care of a child with ASD places high psychological and physical demands on caregivers, potentially aggravating emotional instability, which is likely to interfere with caregivers' attempts to adapt to the situation, resulting in increased and persistent caregiving stress, which may in turn impact the effectiveness of interventions for parents (Jang, Clay, Roth, Haley, \& Mittelman, 2004). Interventions may be improved by understanding the underlying mechanisms between personality traits and caregiver burden because coping strategies and social support are modifiable. Levels of personality traits may help to identify caregiver capacity to manage the care of an individual with ASD and the resources caregivers may need (e.g., adaptive coping strategies, information support). For example, individuals high in neuroticism tend to engage in poor coping efforts (Glidden, Billings, \& Jobe, 2006; Melo et al., 2011) and are low in self-efficacy (Lockenoff et al., 2011). Consistent with these findings, Marziali and colleagues (2010) suggested that community services should adjust to person-specific factors, such as personality, so that caregivers who are at risk or more vulnerable due to individual factors could obtain support services that take into account their vulnerability.

\section{Future Directions}


Future work using longitudinal designs is needed to examine family adaptation over time, especially the long-term adaptation in families after critical transition periods, and to unravel potential causal pathways between potential predictors and caregiver outcomes. As suggested by Friedman and Kern (2014), personality traits may act along with other factors (e.g., genetic predispositions, environmental influences) to impact individuals' lifestyle patterns, such as health behaviors or coping strategies, with downstream effects on subjective well-being and physical health. More detailed and sophisticated models of personality impacts on caregiver outcomes will help clarify causal pathways and provide better guidance for effective interventions (Friedman \& Kern, 2014). Future studies also might benefit from using multidimensional caregiver outcome measures, both subjective (e.g., marital and family adjustment, quality of life) and objective (e.g., longevity, productivity, cognitive function), to provide a more comprehensive assessment of family functioning (Friedman \& Kern, 2014). 


\section{References}

Abbeduto, L., Seltzer, M. M., Shattuck, P., Krauss, M. W., Orsmond, G., \& Murphy, M. M. (2004). Psychological well-being and coping in mothers of youths with autism, Down syndrome, or fragile X syndrome. American Journal of Mental Retardation : AJMR, 109(3), 237-254. https://doi.org/10.1352/0895-8017(2004)109<237:PWACIM>2.0.CO;2

Ballaban-Gil, K., Rapin, I., Tuchman, R., \& Shinnar, S. (1996). Longitudinal examination of the behavioral, language, and social changes in a population of adolescents and young adults with autistic disorder. Pediatr Neurol, 15(3), 217-223. https://doi.org/10.1016/S08878994(96)00219-6

Barker, E. T., Hartley, S. L., Seltzer, M. M., Floyd, F. J., Greenberg, J. S., \& Orsmond, G. I. (2011). Trajectories of emotional well-being in mothers of adolescents and adults with autism. Developmental Psychology, 47(2), 551-561. https://doi.org/10.1037/a0021268

Baum, A., Fleming, R., \& Singer, J. E. (1983). Coping with victimization by technological disaster. Journal of Social Issues, 39(2), 117-138. https://doi.org/10.1111/j.15404560.1983.tb00144.x

Bekhet, A. K., Johnson, N. L., \& Zauszniewski, J. A. (2012). Resilience in family members of persons with autism spectrum disorder: A review of the literature. Issues in Mental Health Nursing, 33(10), 650-656. https://doi.org/10.3109/01612840.2012.671441

Benjamini, Y., \& Hochberg, Y. (1995). Controlling the false discovery rate: A practical and powerful approach to multiple testing. Journal of the Royal Statistical Society Series B, 57(1), 289-300.

Benson, P. R. (2010). Coping, distress, and well-being in mothers of children with autism. 
Research in Autism Spectrum Disorders, 4(2), 217-228.

https://doi.org/10.1016/j.rasd.2009.09.008

Benson, P. R., \& Kersh, J. (2011). Marital quality and psychological adjustment among mothers of children with ASD: Cross-sectional and longitudinal relationships. Journal of Autism and Developmental Disorders, 41(12), 1675-1685. https://doi.org/10.1007/s10803-011-1198-9

Bianco, M., Garrison-Wade, D. F., Tobin, R., \& Lehmann, J. P. (2009). Parents' perceptions of postschool years for young adults with developmental disabilities. Intellectual and Developmental Disabilities, 47(3), 186-196. https://doi.org/10.1352/1934-9556-47.3.186

Blacher, J. (2001). Transition to adulthood: mental retardation, families, and culture. American Journal of Mental Retardation : AJMR, 106(2), 173-188. https://doi.org/10.1352/08958017(2001)106<0173:TTAMRF $>2.0 . \mathrm{CO} ; 2$

Brannan, A. M., Heflinger, C. A., \& Bickman, L. (1997). The caregiver strain questionnaire: Measuring the impact on the family of living with a child with serious emotional disturbance. Journal of Emotional and Behavioral Disorders, 5(4), 212-222. https://doi.org/10.1177/106342669700500404

Bristol, M. M. (1987). Mothers of children with autism or communication disorders: Successful adaptation and the double ABCX model. Journal of Autism and Developmental Disorders, 17(4), 469-486. https://doi.org/10.1007/BF01486964

Cadman, T., Eklund, H., Howley, D., Hayward, H., Clarke, H., Findon, J., ... Glaser, K. (2012). Caregiver burden as people with autism spectrum disorder and attentiondeficit/hyperactivity disorder transition into adolescence and adulthood in the United Kingdom. Journal of the American Academy of Child and Adolescent Psychiatry, 51(9), 
879-888.

Campbell, P., Wright, J., Oyebode, J., Job, D., Crome, P., Bentham, P., ... Lendon, C. (2008). Determinants of burden in those who care for someone with dementia. International Journal of Geriatric Psychiatry, 23(10), 1078-85. https://doi.org/10.1002/gps.2071

Carver, C. S. (1997). You want to measure coping but your protocol's too long: Consider the Brief COPE. International Journal Of Behavioral Medicine. https://doi.org/10.1207/s15327558ijbm0401_6

Casey, L. B., Zanksas, S., Meindl, J. N., Parra, G. R., Cogdal, P., \& Powell, K. (2012). Parental symptoms of posttraumatic stress following a child's diagnosis of autism spectrum disorder: A pilot study. Research in Autism Spectrum Disorders, 6(3), 1186-1193. https://doi.org/10.1016/j.rasd.2012.03.008

Casler, K., Bickel, L., \& Hackett, E. (2013). Separate but equal? A comparison of participants and data gathered via Amazon's MTurk, social media, and face-to-face behavioral testing. Computers in Human Behavior, 29(6), 2156-2160. https://doi.org/10.1016/j.chb.2013.05.009

Chambers, C., Hughes, C., \& Carter, E. (2004). Parent and sibling perspectives on the transition to adulthood. Education and Training in, 39(2), 79-94. Retrieved from http://www.jstor.org/stable/23880058

Chituc, V., Henne, P., Sinnott-Armstrong, W., \& De Brigard, F. (2016). Blame, not ability, impacts moral "ought" judgments for impossible actions: Toward an empirical refutation of “ought” implies "can." Cognition, 150, 20-25. https://doi.org/10.1016/j.cognition.2016.01.013 
Connor-Smith, J. K., \& Flachsbart, C. (2007). Relations between personality and coping: A meta-analysis. Journal of Personality and Social Psychology, 93(6), 1080-1107. https://doi.org/10.1037/0022-3514.93.6.1080

Costa, P. T., \& McCrae, R. R. (1992). Four ways five factors are basic. Personality and Individual Differences, 13(6), 653-665. https://doi.org/10.1016/0191-8869(92)90236-I

Davis, N. O., \& Carter, A. S. (2008). Parenting stress in mothers and fathers of toddlers with autism spectrum disorders: Associations with child characteristics. Journal of Autism and Developmental Disorders, 38(7), 1278-1291. https://doi.org/10.1007/s10803-007-0512-z

Dunn, M., \& Burbine, T. (2001). Moderators of stress in parents of children with autism. Community Mental Health ..., 37(1), 39-52. Retrieved from http://link.springer.com/article/10.1023/A:1026592305436

Dworkin, J., Hessel, H., Gliske, K., \& Rudi, J. H. (2016). A comparison of three online recruitment strategies for engaging parents. Family Relations, 65(4), 550-561. https://doi.org/10.1111/fare.12206

Ekas, N. V., Lickenbrock, D. M., \& Whitman, T. L. (2010). Optimism, social support, and wellbeing in mothers of children with autism spectrum disorder. Journal of Autism and Developmental Disorders, 40(10), 1274-1284. https://doi.org/10.1007/s10803-010-0986-y

Folkman, S., Lazarus, R. S., Dunkel-Schetter, C., DeLongis, A., \& Gruen, R. J. (1986). Dynamics of a stressful encounter: Cognitive appraisal, coping, and encounter outcomes. Journal of Personality and Social Psychology, 50(5), 992-1003. https://doi.org/10.1037/0022-3514.50.5.992

Friedman, H. S., \& Kern, M. L. (2014). Personality, Well-Being, and Health. Annual Review of 
Psychology, 65(1), 719-742. https://doi.org/10.1146/annurev-psych-010213-115123

Gill, M. J., \& Harris, S. L. (1991). Hardiness and social support as predictors of psychological discomfort in mothers of children with autism. Journal of Autism and Developmental Disorders, 21(4), 407-416.

Glidden, L. M. (1993). What we do not know about families with children who have developmental-disabilities - Questionnaire on resources and stress as a case-study. American Journal on Mental Retardation, 97(5), 481-495.

Glidden, L. M., Billings, F. J., \& Jobe, B. M. (2006). Personality, coping style and well-being of parents rearing children with developmental disabilities. Journal of Intellectual Disability Research, 50(12), 949-962. https://doi.org/10.1111/j.1365-2788.2006.00929.x

Hall, H. R., \& Graff, J. C. (2012). Maladaptive behaviors of children with autism: parent support, stress, and coping. Issues in Comprehensive Pediatric Nursing, 35(3-4), 194-214. https://doi.org/10.3109/01460862.2012.734210

Hanley-maxwell, C., Whitney-thomas, J., \& Pogoloff, S. M. (1995). The second shock: A qualitative study of parents' perspectives and needs during their child's transition from school to adult life. Research and Practice for Persons with Severe Disabilities, 20(1), 315.

Hastings, R. P., Kovshoff, H., Brown, T., Ward, N. J., Espinosa, F. D., \& Remington, B. (2005). Coping strategies in mothers and fathers of preschool and school-age children with autism. Autism : The International Journal of Research and Practice, 9(4), 377-391. https://doi.org/10.1177/1362361305056078

Hayes, A. (2013). Introduction to mediation, moderation, and conditional process analysis. New 
York, NY: Guilford, 3-4. https://doi.org/978-1-60918-230-4

Hayes, S. A., \& Watson, S. L. (2013). The impact of parenting stress: A meta-analysis of studies comparing the experience of parenting stress in parents of children with and without autism spectrum disorder. Journal of Autism and Developmental Disorders, 43(3), 629-642. https://doi.org/10.1007/s10803-012-1604-y

Hoffman, C. D., Sweeney, D. P., Hodge, D., Lopez-Wagner, M. C., \& Looney, L. (2009). Parenting stress and closeness mothers of typically developing children and mothers of children with autism. Focus on Autism and Other Developmental Disabilities. https://doi.org/10.1177/1088357609338715

Holahan, C. J., Moos, R. H., Holahan, C. K., Brennan, P. L., \& Schutte, K. K. (2005). Stress generation, avoidance coping, and depressive symptoms: A 10-year model. Journal of Consulting and Clinical Psychology, 73(4), 658-66. https://doi.org/10.1037/0022006X.73.4.658

Holmes, T. H., \& Rahe, R. H. (1967). The social readjustment rating scale. Journal of Psychosomatic Research, 11(2), 213-218. https://doi.org/10.1016/0022-3999(67)90010-4

Hooker, K., Monahan, D., Shifren, K., \& Hutchinson, C. (1992). Mental and physical health of spouse caregivers: The role of personality. Psychology and Aging, 7(3), 367-375. https://doi.org/10.1037/0882-7974.7.3.367

Howlin, P., Goode, S., Hutton, J., \& Rutter, M. (2004). Adult outcome for children with autism. Journal of Child Psychology and Psychiatry, 45(2), 212-229.

IBM Corp. Released. (2015). IBM SPSS Statistics for Windows, Version 23.0. 2015.

Ingersoll, B., \& Hambrick, D. Z. (2011). The relationship between the broader autism phenotype, 
child severity, and stress and depression in parents of children with autism spectrum disorders. Research in Autism Spectrum Disorders, 5(1), 337-344.

https://doi.org/10.1016/j.rasd.2010.04.017

Jang, Y., Clay, O. J., Roth, D. L., Haley, W. E., \& Mittelman, M. S. (2004). Neuroticism and longitudinal change in caregiver depression: Impact of a spouse-caregiver intervention program. The Gerontologist. https://doi.org/10.1093/geront/44.3.311

Jobe, B. M., \& Glidden, L. M. (2008). Predicting maternal rewards and worries for the transition to adulthood of children with developmental disabilities. Journal on Developmental Disabilities, 14(1), 73-84.

Joseph, R. A., Goodfellow, L. M., \& Simko, L. C. (2014). Double ABCX model of stress and adaptation in the context of families that care for children with a tracheostomy at home: Application of a theory. Advances in Neonatal Care: Official Journal of the National Association of Neonatal Nurses, 14(3), 172-80.

https://doi.org/10.1097/ANC.0000000000000062

Kausar, R., \& Powell, G. E. (1999). Coping with caring : Cognitive appraisal of post-onset personality and physical changes in patients with neurological disorders. Stroke, 79, 70.

Khanna, R., Madhavan, S. S., Smith, M. J., Patrick, J. H., Tworek, C., \& Becker-Cottrill, B. (2011). Assessment of health-related quality of life among primary caregivers of children with Autism Spectrum Disorders. Journal of Autism and Developmental Disorders, 41(9), 1214-1227. https://doi.org/10.1007/s10803-010-1140-6

Khanna, R., Madhavan, S. S., Smith, M. J., Tworek, C., Patrick, J. H., \& Becker-Cottrill, B. (2012). Psychometric properties of the Caregiver Strain Questionnaire (CGSQ) among 
caregivers of children with autism. Autism, 16(2), 179-199.

https://doi.org/10.1177/1362361311406143

Kim, Y., Duberstein, P. R., Sörensen, S., \& Larson, M. R. (2005). Levels of depressive symptoms in spouses of people with lung cancer: Effects of personality, social support, and caregiving burden. Psychosomatics, 46(2), 123-30. https://doi.org/10.1176/appi.psy.46.2.123

Kirby, A. V., White, T. J., \& Baranek, G. T. (2015). Caregiver strain and sensory features in children with autism spectrum disorder and other developmental disabilities. American Journal on Intellectual and Developmental Disabilities, 120(1), 32-45. https://doi.org/10.1352/1944-7558-120.1.32

Lautenschlager, N., Kurz, A., Loi, S., \& Cramer, P. (2013). Personality of mental healthcaregivers. Current Opinion in Psychiatry, 26(1), 97-101. https://doi.org/10.1097/YCO.0b013e32835997b3

Lazarus, R. S. (1990). Theory-based stress measurement. Psychological Inquiry, 1(1), 3-13. https://doi.org/10.1207/s15327965pli0101_1

Lazarus, R. S., \& Folkman, S. (1984). Coping and adaptation. In The Handbook of Behavioral Medicine . (pp. 282-325). https://doi.org/http://dx.doi.org/10.1016/S0002-7138(09)61635-6

Löckenhoff, C. E., Duberstein, P. R., Friedman, B., \& Costa, P. T. (2011). Five-factor personality traits and subjective health among caregivers: the role of caregiver strain and self-efficacy. Psychology and Aging, 26(3), 592-604. https://doi.org/10.1037/a0022209

Manning, M. M., Wainwright, L., \& Bennett, J. (2011). The double ABCX model of adaptation in racially diverse families with a school-age child with autism. Journal of Autism and 
Developmental Disorders, 41(3), 320-331. https://doi.org/10.1007/s10803-010-1056-1

Marziali, E., McCleary, L., \& Streiner, D. L. (2010). Evaluation of an assessment battery for estimating dementia caregiver needs for health and social care services. American Journal of Alzheimer's Disease and Other Dementias, 25(5), 446-454. https://doi.org/10.1177/1533317510370958

McCausland, J., \& Pakenham, K. I. (2003). Investigation of the benefits of HIV/AIDS caregiving and relations among caregiving adjustment, benefit finding, and stress and coping variables. AIDS Care, 15(6), 853-869. https://doi.org/10.1080/09540120310001618694

McCubbin, H. I., \& Patterson, J. M. (1983). The family stress process: The double ABCX model of adjustment and adaptation. Social Stress and the Family: Advances and Developments in Family Stress Theory and Research, 6(1-2), 7-37. https://doi.org/10.1300/J002v06n01_02

McGrew, J. H., \& Keyes, M. L. (2014). Caregiver stress during the first year after diagnosis of an autism spectrum Disorder. Research in Autism Spectrum Disorders, 8(10), 1373-1385. https://doi.org/10.1016/j.rasd.2014.07.011

Mcstay, R. L., Trembath, D., \& Dissanayake, C. (2014). Stress and family quality of life in parents of children with autism spectrum disorder: Parent gender and the double ABCX model. Journal of Autism and Developmental Disorders, 44(12), 3101-3118. https://doi.org/10.1007/s10803-014-2178-7

Melo, G., Maroco, J., \& De Mendonça, A. (2011). Influence of personality on caregiver's burden, depression and distress related to the BPSD. International Journal of Geriatric Psychiatry, 26(12), 1275-1282. https://doi.org/10.1002/gps.2677

Nelson, D. L., \& Sutton, C. (1990). Chronic work stress and coping: A longitudinal study and 
suggested new directions. The Academy of Management Journal, 33(4), 859-869.

https://doi.org/10.2307/256295

Pakenham, K. I. (2001). Application of a stress and coping model to caregiving in multiple sclerosis. Psychology, Health \& Medicine, 6(1), 13-27.

https://doi.org/10.1080/13548500125141

Pakenham, K. I., Samios, C., \& Sofronoff, K. (2005). Adjustment in mothers of children with Asperger syndrome: an application of the double ABCX model of family adjustment. Autism, 9(2), 191-212. https://doi.org/10.1177/1362361305049033

Paynter, J., Riley, E., Beamish, W., Davies, M., \& Milford, T. (2013). The double ABCX model of family adaptation in families of a child with an autism spectrum disorder attending an Australian early intervention service. Research in Autism Spectrum Disorders, 7(10), 11831195. https://doi.org/10.1016/j.rasd.2013.07.006

Peacock, E. J., \& Wong, P. T. P. (1990). The stress appraisal measure (SAM): A multidimensional approach to cognitive appraisal. Stress Medicine, 6(3), 227-236. https://doi.org/10.1002/smi.2460060308

Pearlin, L. I., \& Schooler, C. (1978). The structure of coping. Journal of Health and Social Behavior Journal of Health and Social Behavior, 19(19), 2-212. https://doi.org/10.2307/2136319

Penley, J. A., \& Tomaka, J. (2002). Associations among the Big Five, emotional responses, and coping with acute stress. Personality and Individual Differences, 32(7), 1215-1228. https://doi.org/10.1016/S0191-8869(01)00087-3

Penley, J. A., Tomaka, J., \& Wiebe, J. S. (2002). The association of coping to physical and 
psychological health outcomes: A meta-analytic review. J.Behav.Med., 25(6), 551-603. https://doi.org/10.1023/A:1020641400589

Pennarola, B. W., Rodday, A. M., Mayer, D. K., Ratichek, S. J., Davies, S. M., Syrjala, K. L., ... Parsons, S. K. (2012). Factors associated with parental activation in pediatric hematopoietic stem cell transplant. Medical Care Research and Review : MCRR, 69(2), 194-214. https://doi.org/10.1177/1077558711431460

Pottie, C. G., \& Ingram, K. M. (2008). Daily stress, coping, and well-being in parents of children with autism: a multilevel modeling approach. Journal of Family Psychology, 22(6), 855864. https://doi.org/10.1037/a0013604

Pozo, P., Sarriá, E., \& Brioso, A. (2013). Family quality of life and psychological well-being in parents of children with autism spectrum disorders: A double ABCX model. Journal of Intellectual Disability Research, 58(may), 442-458. https://doi.org/10.1111/jir.12042

Prinzie, P., Stams, G. J. J. M., Deković, M., Reijntjes, A. H. A., \& Belsky, J. (2009). The relations between parents' Big Five personality factors and parenting: A meta-analytic review. Journal of Personality and Social Psychology, 97(2), 351-362. https://doi.org/10.1037/a0015823

Rantanen, J., Tillemann, K., Metsapelto, R. L., Kokko, K., \& Pulkkinen, L. (2015). Longitudinal study on reciprocity between personality traits and parenting stress. International Journal of Behavioral Development, 39(1), 65-76. https://doi.org/10.1177/0165025414548776

Reis, M. F., Gold, D. P., Andres, D., Markiewicz, D., \& Gauthier, S. (1994). Personality traits as determinants of burden and health complaints in caregiving. International Journal of Aging \& Human Development, 39(3), 257-271. 
Robins, R. W., Fraley, R. C., Roberts, B. W., \& Trzesniewski, K. H. (2001). A longitudinal study of personality change in young adulthood. Journal of Personality, 69(4), 617-640. https://doi.org/10.1111/1467-6494.694157

Roehrig, M., Thompson, J. K., \& Cafri, G. (2008). Effects of dieting-related messages on psychological and weight control variables. International Journal of Eating Disorders, 41(2), 164-173. https://doi.org/10.1002/eat.20470

Roesch, S. C., \& Rowley, A. A. (2005). Evaluating and developing a multidimensional, dispositional measure of appraisal. Journal of Personality Assessment, 85(2), 188-196. https://doi.org/10.1207/s15327752jpa8502_11

Rutter, M., Bailey, A., \& Lord, C. (2003). Social Communication Questionnaire. Los Angeles, $C A$.

Saloviita, T., Italinna, M., \& Leinonen, E. (2003). Explaining the parental stress of fathers and mothers caring for a child with intellectual disability: A double ABCX model. Journal of Intellectual Disability Research, 47, 300-313. Retrieved from http://web.a.ebscohost.com/ehost/pdfviewer/pdfviewer?sid=238536a6-69cd-4f4d-bbd27539e8efdf7e\%40sessionmgr4010\&vid=4\&hid $=4106$

Shapiro, D. N., Chandler, J., \& Mueller, P. A. (2013). Using mechanical turk to study clinical populations. Clinical Psychological Science, 1(2), 213-220. https://doi.org/10.1177/2167702612469015

Shurgot, G. R., \& Knight, B. G. (2005). Influence of neuroticism, ethnicity, familism, and social support on perceived burden in dementia caregivers: Pilot test of the transactional stress and social support model. The Journals of Gerontology. Series B, Psychological Sciences and 
Social Sciences, 60(6), P331-P334.

Smith, L. E., Greenberg, J. J. S., \& Seltzer, M. M. M. (2012). Social support and well-being at mid-life among mothers of adolescents and adults with autism spectrum disorders. Journal of Autism and Developmental Disorders, 42(9), 1818-1826. https://doi.org/10.1007/s10803$011-1420-9$

Smith, L. E., Seltzer, M. M., Tager-Flusberg, H., Greenberg, J. S., \& Carter, A. S. (2008). A comparative analysis of well-being and coping among mothers of toddlers and mothers of adolescents with ASD. Journal of Autism and Developmental Disorders, 38(5), 876-889. https://doi.org/10.1007/s10803-007-0461-6

Stone, W., Lisa, R., Hepburn, S., Coonrod, E., Burnette, C., Pennington, M., \& Brigham, N. B. (2010). Assessing Children with Autism Spectrum Disorders.

Stuart, M., \& McGrew, J. H. (2009). Caregiver burden after receiving a diagnosis of an autism spectrum disorder. Research in Autism Spectrum Disorders, 3(1), 86-97. https://doi.org/10.1016/j.rasd.2008.04.006

Van Bourgondien, M. E., Dawkins, T., \& Marcus, L. (2014). Families of adults with autism spectrum disorders. In Adolescents and Adults with Autism Spectrum Disorders (pp. 15-40). https://doi.org/10.1007/978-1-4939-0506-5_2

Van der Lee, J., Bakker, T. J. E. M., Duivenvoorden, H. J., \& Dröes, R. M. (2014). Multivariate models of subjective caregiver burden in dementia: A systematic review. Ageing Research Reviews, 15(1), 76-93. https://doi.org/10.1016/j.arr.2014.03.003

White, N., \& Hastings, R. (2004). Social and professional support for parents of adolescents with severe intellectual disabilities. Journal of Applied Research in Intellectual Disabilities, 
17(3), 181-190. https://doi.org/http://dx.doi.org/10.1111/j.1468-3148.2004.00197.x

Zarit, S. H., Todd, P. A., \& Zarit, J. M. (1986). Subjective burden of husbands and wives as caregivers: a longitudinal study. The Gerontologist, 26(3), 260-266. https://doi.org/10.1093/geront/26.3.260

Zimet, G. D., Dahlemet, N. W., Zimet, S. G., Farley, G. K. G., Dahlem, N. W., Zimet, S. G., \& Farley, G. K. G. (1988). The multidimensional scale of perceived social support. Journal of Personality Assessment, 52(1), 30-41. https://doi.org/10.1207/s15327752jpa5201_2 
Table 1

Demographic Information of Caregivers and Their Children with ASD

\begin{tabular}{|c|c|c|c|}
\hline Parent Variables & $M(S D)$ & $n$ & $\%$ \\
\hline Age & $42.99(5.35)$ & & \\
\hline \multicolumn{4}{|l|}{ Gender } \\
\hline Male & & 57 & 54.3 \\
\hline Female & & 48 & 45.7 \\
\hline \multicolumn{4}{|l|}{ Race } \\
\hline White & & 88 & 83.8 \\
\hline \multicolumn{4}{|l|}{ Current Relationship Status } \\
\hline Married or cohabitation & & 81 & 77.1 \\
\hline \multicolumn{4}{|l|}{ Employment Status } \\
\hline Working Full Time (35 + Hours a Week) & & 82 & 78.1 \\
\hline Others (e.g., working part time, homemaker) & & 23 & 21.9 \\
\hline \multicolumn{4}{|l|}{ Education Level } \\
\hline High School or below & & 17 & 16.2 \\
\hline Some College or Technical or Trade School & & 29 & 27.6 \\
\hline College Graduate & & 49 & 46.7 \\
\hline Advanced Graduate or Professional Degree & & 9 & 8.6 \\
\hline \multicolumn{4}{|l|}{ Annual Income } \\
\hline Less than or equal to $\$ 60,000$ & & 56 & 53.3 \\
\hline More than $\$ 60,001-\$ 80,000$ & & 46 & 43.8 \\
\hline Children With ASD & $M(S D)$ & $n$ & $\%$ \\
\hline Child's Age & $17.40(1.50)$ & & \\
\hline \multicolumn{4}{|l|}{ Gender } \\
\hline Male & & 86 & 81.9 \\
\hline Female & & 19 & 18.1 \\
\hline \multicolumn{4}{|l|}{ Child's Status After Graduating From High School } \\
\hline Work/Employment & & 14 & 13.3 \\
\hline School (i.e., College/University, Vocational School, & & 65 & 61.9 \\
\hline
\end{tabular}




\section{Community College}

Others (e.g., Day Program, Stay Home)

$26 \quad 24.8$

Child's Living Situation After Graduating From High School

$\begin{array}{lll}\text { Living Independently } & 6 & 5.7\end{array}$

Living Independently but with Assistance $\quad 12 \quad 11.4$

Residential Placement $\quad \begin{array}{ll}1 & 1.0\end{array}$

$\begin{array}{lll}\text { Live with Parents } & 84 & 80.0\end{array}$

Other: Undecided, Dorm and Home $\quad 2 \quad 1.9$

Note. ASD = autism spectrum disorder. 
Table 2

Study Variables Means, Standard Deviations, and Confidence Intervals

\begin{tabular}{|c|c|c|c|c|}
\hline \multirow{2}{*}{$\begin{array}{l}\text { Variables } \\
\text { Independent Variables }\end{array}$} & \multirow[t]{2}{*}{$M$} & \multirow[t]{2}{*}{$S D$} & \multicolumn{2}{|c|}{$95 \% \mathrm{CI}$} \\
\hline & & & $L L$ & $U L$ \\
\hline Symptom Severity & 18.70 & 4.62 & 17.81 & 19.60 \\
\hline Problem Behavior & 2.04 & 0.48 & 1.95 & 2.13 \\
\hline Pile-up Demands & 18.07 & 14.69 & 15.22 & 20.91 \\
\hline Transition-related Demands & 2.90 & 0.89 & 2.73 & 3.07 \\
\hline \multicolumn{5}{|l|}{ Personality Traits } \\
\hline Neuroticism & 30.89 & 9.46 & 29.05 & 32.72 \\
\hline Extraversion & 39.50 & 7.14 & 38.12 & 40.89 \\
\hline Conscientiousness & 46.88 & 6.07 & 45.70 & 48.05 \\
\hline Openness & 40.17 & 6.80 & 38.86 & 41.49 \\
\hline Agreeableness & 42.34 & 5.54 & 41.27 & 43.41 \\
\hline \multicolumn{5}{|l|}{ Social Support } \\
\hline General Social Support & 5.57 & 1.08 & 5.36 & 5.78 \\
\hline Contextual Social Support & 5.20 & 1.20 & 4.97 & 5.43 \\
\hline \multicolumn{5}{|l|}{ Cognitive Appraisal Styles } \\
\hline Threat Appraisal & 2.28 & 0.74 & 2.14 & 2.42 \\
\hline Challenge Appraisal & 3.24 & 0.70 & 3.10 & 3.37 \\
\hline \multicolumn{5}{|l|}{ Coping Strategies } \\
\hline Problem-focused Coping & 2.86 & 0.65 & 2.74 & 2.99 \\
\hline Passive-avoidance Coping & 1.62 & 0.43 & 1.53 & 1.70 \\
\hline Emotional Approach coping & 2.44 & 0.54 & 2.34 & 2.54 \\
\hline \multicolumn{5}{|l|}{ Dependent Variables } \\
\hline Caregiver Burden & 2.13 & 0.74 & 1.98 & 2.27 \\
\hline Objective Strain & 2.05 & 0.76 & 1.91 & 2.20 \\
\hline Internalized Subjective Strain & 2.55 & 0.92 & 2.37 & 2.73 \\
\hline Externalized Subjective Strain & 1.69 & 0.85 & 1.52 & 1.85 \\
\hline
\end{tabular}

Note. $\mathrm{CI}=$ confidence interval; $L L=$ lower limit, $U L=$ upper limit. 
Table 3

Correlation Analyses between Caregiver Burden and Independent Variables

\section{Independent Variables}

Autism symptom severity

Problem behaviors

Pile-up demands

Transition-related demands

Neuroticism

Extraversion

Conscientiousness

Openness

Agreeableness

General social support

Community social support

Threat appraisal

Challenge appraisal

Problem-focused coping

Passive-avoidance coping

Emotional approach coping

\section{Caregiver burden}

\begin{tabular}{ll} 
Pearson $r$ & $p$ \\
\hline $.25^{* *}$ & 0.006 \\
$.50^{* *}$ & 0.000 \\
$.20^{*}$ & 0.021 \\
$.28^{+}$ & 0.003 \\
$.46^{* *}$ & 0.000 \\
$-.26^{* *}$ & 0.004 \\
$-.31^{* *}$ & 0.001 \\
$-.19^{+}$ & 0.048 \\
$-.21^{+}$ & 0.030 \\
$-.31^{* *}$ & 0.001 \\
$-.19^{*}$ & 0.028 \\
$.48^{* *}$ & 0.000 \\
-.11 & 0.135 \\
.10 & 0.156 \\
$.69^{* *}$ & 0.000 \\
.08 & 0.203
\end{tabular}

${ }^{* *} p<.01$, one-tailed. ${ }^{*} p<.05$, one-tailed. ${ }^{+} p<.05$, two-tailed. 
Table 4

Summary of Hierarchical Regression Analysis for Variables Predicting Caregiver Burden

\begin{tabular}{|c|c|c|c|}
\hline & \multirow[t]{2}{*}{ Predictors } & \multicolumn{2}{|c|}{ Caregiver Burden } \\
\hline & & $\boldsymbol{\beta}$ & $\Delta R^{2}$ \\
\hline Model 1 & Receiving therapy or not & 0.12 & .04 \\
\hline \multirow[t]{2}{*}{ Model 2} & Symptom Severity & 0.03 & .24 \\
\hline & Problem Behaviors & $0.25^{*}$ & \\
\hline \multirow[t]{2}{*}{ Model 3} & Pile-up Demands & -0.01 & .01 \\
\hline & Transition-related Demands & 0.05 & \\
\hline \multirow[t]{3}{*}{ Model 4} & Neuroticism & 0.05 & .14 \\
\hline & Extraversion & 0.02 & \\
\hline & Conscientiousness & -0.09 & \\
\hline \multirow[t]{2}{*}{ Model 5} & General Social Support & -0.17 & .02 \\
\hline & Contextual Social Support & 0.01 & \\
\hline \multirow[t]{2}{*}{ Model 6} & Threat Appraisal & 0.14 & .06 \\
\hline & Challenge Appraisal & -0.03 & \\
\hline \multirow[t]{3}{*}{ Model 7} & Problem-focused Coping & 0.19 & .12 \\
\hline & Passive-avoidance Coping & $0.41 *$ & \\
\hline & Emotional approach Coping & -0.06 & \\
\hline Total $R^{2}$ & & 0.63 & \\
\hline
\end{tabular}

${ }^{\mathrm{a}} N=105$.

$* p<.05$. 
Table 5

Double ABCX Model Elements, Measures to Assess Elements, and Internal Consistency of Study Measures

\begin{tabular}{|c|c|c|c|c|}
\hline Double ABCX Model & Measures & $\begin{array}{l}\text { Internal } \\
\text { Consistency }\end{array}$ & $\begin{array}{l}\text { Included in } \\
\text { Regression }\end{array}$ & $\begin{array}{l}\text { Included in } \\
\text { Mediation }\end{array}$ \\
\hline \multicolumn{5}{|l|}{ Stressor (A) } \\
\hline Autism symptom severity & SCQ & .60 & Yes & \\
\hline Problem behaviors & PBRS & .92 & Yes & \\
\hline \multicolumn{5}{|l|}{ Pile-up demands (aA) } \\
\hline Recent life events & SRRS & .90 & Yes & \\
\hline Transition-related demands & TSQ & .81 & Yes & \\
\hline \multicolumn{5}{|l|}{ Internal Resources (B) } \\
\hline Big Five Personality Traits & NEO-FFI & .74 & & \\
\hline Neuroticism & & .90 & Yes & Yes \\
\hline Extraversion & & .83 & Yes & Yes \\
\hline Conscientiousness & & .82 & Yes & Yes \\
\hline Openness & & .74 & & \\
\hline Agreeableness & & .70 & & \\
\hline \multicolumn{5}{|l|}{ External Resources (bB) } \\
\hline General Social Support & MSPSS & .96 & Yes & Yes \\
\hline Contextual Social Support & CPSS & .94 & Yes & Yes \\
\hline Cognitive Appraisal (C) & SAM & & & \\
\hline Threat Appraisals & & .70 & Yes & Yes \\
\hline Challenge Appraisals & & .67 & Yes & Yes \\
\hline Coping Strategies (cC) & Brief Cope & & & \\
\hline Problem-focused coping & & .84 & Yes & Yes \\
\hline Passive-avoidance coping & & .81 & Yes & Yes \\
\hline Emotional approach coping & & .77 & Yes & Yes \\
\hline \multicolumn{5}{|l|}{ Outcome $(X)$} \\
\hline Individual caregiving burden & CGSQ & .94 & Yes & Yes \\
\hline Objective Strain & & .87 & & \\
\hline Internalized Subjective Strain & & .87 & & \\
\hline Externalized Subjective Strain & & .84 & & \\
\hline
\end{tabular}

Note. SCQ = Social Communication Questionnaire; PBRS = Problem Behavior Rating Scale; SRRS = Social Readjustment Rating Scale; TSQ = Transition Stressor Questionnaires; NEO-FFI = Neo Five Factor Index; MSPSS = Multidimensional Scale of Perceived Social Support; CPSS = Contextual Perceived Social Support; $\mathrm{SAM}=$ Stress Appraisal Measure; CGSQ = Caregiver Strain Questionnaire. 


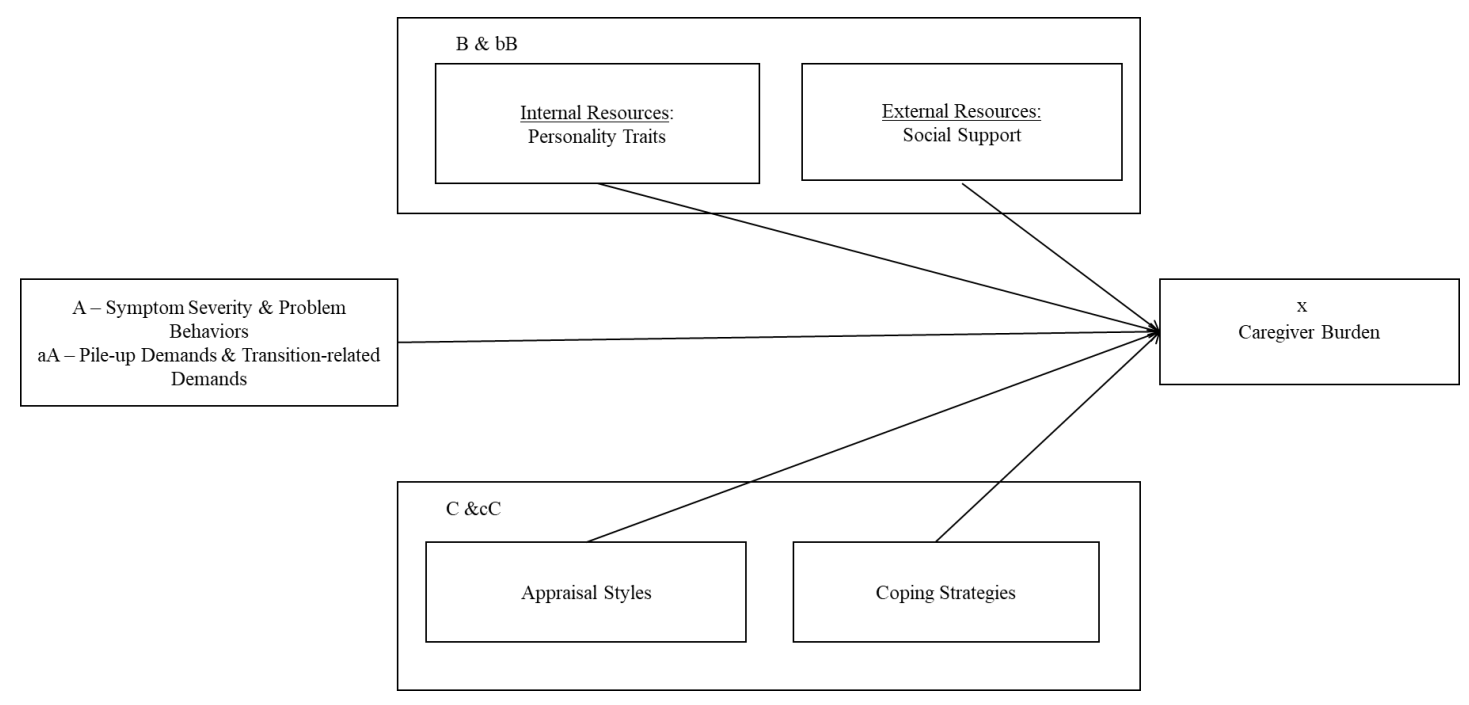

Figure 1. The double ABCX model.

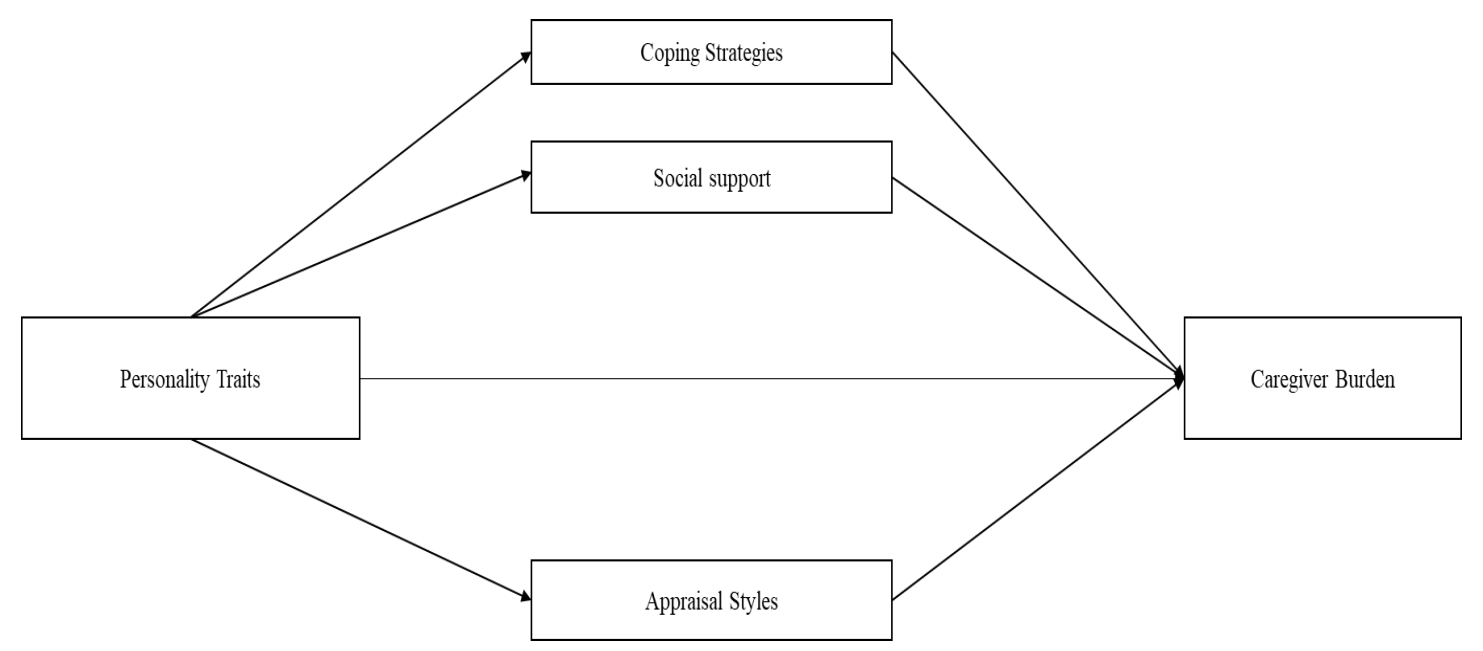

Figure 2. Conceptual model for parallel mediation analyses between personality traits and caregiver burden. 
Appendix A. Transition Stressor Questionnaire (TSQ)

Directions: Please choose a number from the following scale to indicate your answer to each of the following questions. Place the number in the box to the right of each question.

$\begin{array}{ccccc}1 & 2 & 3 & 4 & 5 \\ \text { NONE } & \text { A LITTLE BIT } & \text { SOME } & \text { A FAIR AMOUNT } & \text { A LOT }\end{array}$

1. How much effort have you and your family put into planning for your child's transition out of high school?

a. Approximately how many hours?

1. How much time and energy have you spent thinking about, actively pursuing answers about, or discussing with other people your child's transition?

a. Approximately how many hours?

3. How much has planning your child's transition out of high school required you to change your family activities?

4. How much has planning your child's transition out of high school required you to change your social activities?

5. How much has planning your child's s transition out of high school required you to change your work activities?

Table 6

Endorsement of Each Item on the TSQ

\begin{tabular}{llllll}
\hline Items & \multicolumn{5}{c}{ Endorsement Rate (\%) } \\
\hline & $\mathbf{1}$ (None) & $\mathbf{2}$ (A Little Bit) & $\mathbf{3}$ (Some) & $\mathbf{4}$ (A Fair Amount) & $\mathbf{5}$ (A Lot) \\
\cline { 2 - 5 } Item 1 & 2.9 & 7.6 & 23.8 & 41.0 & 24.8 \\
Item 2 & 1.9 & 16.2 & 26.7 & 30.5 & 24.8 \\
Item 3 & 21.0 & 33.3 & 23.8 & 11.4 & 10.5 \\
Item 4 & 34.3 & 22.9 & 23.8 & 11.4 & 6.7 \\
Item 5 & 38.1 & 25.7 & 19.0 & 9.5 & 7.6 \\
\hline
\end{tabular}

Note. TSQ $=$ Transition Stressor Questionnaire 